\title{
The role of standardized patient assessment forms in medical communication skills education
}

\author{
Grace Peters \\ Department of Communication, University of South Florida, Tampa, FL, USA
}

\begin{abstract}
Communication skills training is a routine practice in medical education designed to instruct and evaluate future physicians in matters of patient-provider interaction. Based on the United States Medical Licensing Examination Step 2 Clinical Skills (CS), medical schools across the United States hire and train standardized patients (SPs) to act as patients in and evaluators of simulated interactions with medical students (MSs). Using discourse analysis, I examine how a computerized assessment form creates a particularized version of communication skills with implications for future practice. The 39-item checklist is completed by SPs following a simulated interaction designed to prepare third-year MSs for the Step 2 CS. Specifically, I analyze how the form is structured to make recognizable specific communication skills tasks, who should complete said tasks, and what varying degrees of communication skills competency are within the realm of task completion. By analyzing the form, I consider the agency of texts in medical education, the implications of technologizing communication as an institutional skill, and the limitations of enlisting SPs to evaluate communication skills competency under the guise of a patient perspective.
\end{abstract}

\section{Introduction}

\section{Communication skills as metadiscursive artifact}

Communication is said to be one of the most influential means of how physicians demonstrate professional

Correspondence: Grace Peters, Department of Communication, University of South Florida, 4202 E. Fowler Avenue, CIS 1040 Tampa, FL 33620, USA.

E-mail: gem@mail.usf.edu

Acknowledgments: the author would like to thank Dr. Mariaelena Bartesaghi for her continued guidance and support of this work.

Key words: Medical education; Standardized patients; Discourse analysis; Metadiscourse.

Conflict of interest: the author declares no potential conflict of interest.

Funding: none.

Conference presentation: earlier versions of portions of this paper will be presented at the $105^{\text {th }}$ Annual National Communication Association Convention in Baltimore, MD in November 2019.

Received for publication: 8 April 2019.

Revision received: 25 July 2019.

Accepted for publication: 29 July 2019.

This work is licensed under a Creative Commons Attribution NonCommercial 4.0 License (CC BY-NC 4.0).

${ }^{\circ}$ Copyright: the Author(s), 2019

Licensee PAGEPress, Italy

Qualitative Research in Medicine \& Healthcare 2019; 3:76-86

doi:10.4081/qrmh.2019.8213 competency. A physician with communication skills ensures their patients will better adhere to treatment recommendations, manage their own heath, and report greater satisfaction with their practitioners; in turn physicians will receive a lower incidence of medical malpractice suits, avoid burnout, and increase empathy for their patients. ${ }^{1-3}$ Institutions like the National Institutes of Health and the Association of American Medical Colleges, support and ensure the development of communication skills through governmental programs, curriculum requirements, and licensing practices. ${ }^{4,5}$

Undergirding the value of communication skills in medicine is the assumption that communication is a skill that can be taught and learned. One of the most widely accepted methods for training medical students (MSs) in communication is the use of a standardized or simulated patient (SP). ${ }^{6}$ In use since the $1960 s,{ }^{7}$ SPs are employed and trained by medical schools to portray patients in simulated interactions with MSs and evaluate MSs on those simulated interactions. Although other methods of simulation are used in medical education, including role-play among MSs and technical simulations with mannequins, SPs allow medical educators to create life-like cases with a variety of patient personae and pertinent diagnoses for students to repeatedly practice communication skills and receive feedback from SPs. Such experiential learning is said to actively simulate clinical practices and is the best practice for enhancing student learning of communication skills. ${ }^{8}$ Even MSs claim to prefer this method of communication skills training over other forms of simulation, listening to lectures, meeting with actual patients, or watching video-taped interviews. ${ }^{9}$

While the importance of developing physician communication skills is evidenced by its institutional validation 
and extensive practice, the specifics of its metadiscourse are often overlooked. Metadiscourse or talk about talk reflexively comments on communication, explicating norms of practice, and indexing the importance of communication broadly and in medical education specifically. ${ }^{10}$ Taking a metadiscursive stance acknowledges communication in use as highly contextual and regulatory, meaning it implicitly and explicitly makes suggestions for what constitutes good or bad communication in a given situation. This approach stands in contrast to how communication is typically studied in medical education, as an ex post facto construct that can be measured, assessed, and known. Instead, I employ discourse analysis to examine the metadiscourse of communication skills training with SPs.

Metadiscourse is observable in conversations, narratives, classroom instruction, how-to guides, textbooks, and educational assessments. ${ }^{11-14} \mathrm{I}$ attend to the construction of communication as it occurs in a computerized assessment form completed by SPs after a simulated interaction with third-year MSs, which is designed to prepare them for the Step 2 CS Licensing Exam. The form is designed by a team of faculty and staff that coordinate a large medical school's standardized patient program, the Communication Skills Learning Center (CSCL).

Although the form used at CSCL is specific to its location, it intertextually brings about the metadiscourse of communication skills, meaning the language of the form resonates with the genre of communication skills discourse visible in medical education and health communication research. The intertextual resonance of the form in turn validates its local use, which makes this analysis relevant to other sites of communication skills training in medical education.

I argue the form designates, authorizes, and regulates MS and SP actions by making recognizable specific communication tasks, who should complete said tasks, and what varying degrees of skilled communication are. In practice, the assessment form decontextualizes communication from everyday practice and technologizes it as an institutional practice, which can be measured, assessed, taught, and learned. Based on the results of my analysis, I make practical suggestions to improve SP-based communication skills training, which I argue has impacts for SPs, MSs, and future patients. I ask the following: how does CSCL construct communication skills in a computerized assessment form? What are those communication skills? Who are communication skills relevant for? And what are the implications for current and future medical practice?

\section{Standardized patients in communication skills training}

The ability to evaluate MS's communication skills through role play interactions with SPs hinges on devices that assess student competency. There are dozens of mod- els that aim to describe and measure the best practices of communication, including the Kalamazoo Consensus Statement, ${ }^{15}$ the Rochester Communication Rating Scale, ${ }^{16}$ and the Patient-Perception of Patient Centeredness. ${ }^{17}$ Such models are widely used tools, regarded as valid and reliable means for establishing a general sense of effective patient-provider communication, and considered accurate and effective analyses when completed by SPs. ${ }^{18}$ In a narrative review of communication skills models, King and Hoppe ${ }^{19}$ identify six features of physician communication skills present in nearly every tool: i) foster a relationship with the patient; ii) gather information; iii) provide information; iv) make decisions with a patient; v) appropriately respond to emotions; and vi) enable diseaseand treatment- related behavior. Medical schools are not required to adopt one particular model but instead independently determine what skills should be learned and how to measure competency, often through adopting one particular model, creating an amalgamation of models, or developing their own model, any of which frequently stands in as the communication curriculum. ${ }^{20}$

However, taking a metadiscursive stance on communication skills competency shifts the focus from the validity, reliability, and generalizability of communication skills models to what actually occurs in interaction, which constitutes those skills. To analyze SP practices from a metadiscursive stance, one must take the approach that what agents do in interaction is consequential to local simulated activities, including assessment form completion. Furthermore, taking a metadiscursive stance towards computerized assessment forms offers insight into the professional knowledge of communication skills (p. 192). ${ }^{21}$

In their study of communication skills training with SPs, Atkins et al. ${ }^{22}$ theorize simulation through Goffman's Frame Analysis, to argue talk is always performance in context, especially in professional...and institutional ones (p. 1). Essentially, in simulated contexts, there are multiple interpretive schema or frames available to SPs - performing scripted patients, reflecting the scripted patient's potential emotions, enacting those emotions, and evaluating the MS's communication skills. Similarly, MSs most often recognize the context of simulated interactions as artificial, and orient to performing a good doctor, one who must balance being competent in medical diagnosis and communication skills, all while portraying a sense of authentic self. ${ }^{23}$ The team goes on to note, candidates who can handle the social and linguistic complexity of this somewhat artificial, standardized situation score highly yet what is being assessed is not real communication but the ability to voice a credible appearance of such communication (p. 7). In essence, doing well in a simulated interaction is not ipso facto skilled communication with actual patients.

Similarly, in investigating how successful communication occurs in simulated medical interactions, Roberts and Sarangi ${ }^{24}$ note students achieving high scores are in 
tune with SPs speaking styles and integrate authority with solidarity. In contrast, unsuccessful students are stylistically dissonant, use canned statements that create a sense of trained empathy, and do not take the patient with them. (p. 113). With the goal of communicating their results to medical educators, the discourse analysts challenge psychological notions like empathy or rapport, which are not interactionally visible and instead adopt Gumperz's ${ }^{25}$ view of styles to suggest tools for self-analysis in real patienthealth care professional communication (p. 114). In a follow-up study, Roberts et al. offer a taxonomy of communicative style to accommodate the interactional findings of what makes for good and poor communication in simulated interactions (p. 200). ${ }^{26}$ By creating interactional maps that easily compare communicative styles the team evidences what works and what does not.

However, MSs who are regarded as skilled communicators demonstrate the particular features of communication distinct from actual medical interactions. For instance, Atkins ${ }^{27}$ uses corpus linguistics and conversation analysis to compare simulated and actual general practice consultations, noting that successful MSs use the phrase tell me more about... more often that practicing physicians. Similarly, in a comparative study of simulated and actual patient-provider interactions, De la Croix and Skeleton ${ }^{28}$ note the simulated interactions contain more SP interruptions ( $v s$ doctor interruptions in actual consultations), SP topic selection utterances ( $v s$ physician topic selection utterances in actual consultations), and SPs initiating closing sequences ( $v s$ physicians ending the interaction in actual consultations). In this, they note how both SPs and MSs orient to assessment forms in the simulated interactions as a means for how to go on. Seale et al. ${ }^{29}$ also explain the hybrid nature of simulated interactions, which includes the management of skills-based discourses visible in assessment forms and interpersonal discourses. While simulated interactions do vary from data on patientprovider interactions, they continue to serve as institutional resources. ${ }^{30}$ In sum, skilled communication in the context of simulation is not only different from actual consultations but is often oriented to notions found in institutional documents, like computerized assessment forms.

The broad institutionalization of communication skills models means that medical schools continue to prefer traditional social scientific models that assess ex post facto constructs like empathy rather than develop robust interaction-based tools that allow students to reflexively engage their own performances in both simulated and actual interactions. By taking metadiscursive stance on the study of communication skills, I attend to what actually occurs in SP practices, namely the interactional accomplishment of completing a computerized assessment form. A great deal of attention has been paid to the nature of simulated interactions, but little research attends to how institutional documents, assessment forms in particular, afford and constrain notions of communication skills. I suggest such forms structure and enact agency in forging standards of communication skills competency for simulated interactions. In turn, what makes for a skilled communicator in the context of medical education is an orientation to the standards of evaluation created, regulated, and maintained by institutions of medical education. So, what are those standards? What strategies are used to maintain said standards? And how can one know?

\section{Discourse analysis}

Discourse analysis describes both a metatheoretical orientation towards doing research and a methodological toolkit, which affords a metadiscursive analysis of communication skills. ${ }^{31}$ Metatheoretically, discourse analysts reject hidden or cognitivist explanations in favor of questioning how actors in the visible minutia of everyday life forge reality. ${ }^{32}$ As a discourse analyst, I expand the notion of actors to include nonhuman and human agents. This relational perspective takes a practical turn towards investigating how visible interactions real-ize, or make real the world we live and act in Tracy and Mirivel (p. 154). ${ }^{33-35}$

Anything is data for the discourse analyst: texts, video recordings of face to face interactions, material objects, websites, organizations, etc. In interpreting and analyzing data from the metatheoretical positions described above, I take a synthetic approach to doing discourse analysis meaning I draw on a wide range of empirical methods including conversation analysis, membership category analysis, politeness theory, discursive psychology, interactional sociolinguistics, action-implicative discourse analysis, and critical discourse analysis. ${ }^{36,37}$ The goal in doing discourse analytic work is not to simply describe, summarize, or point out interesting features of interaction, but to $d o$ analysis.$^{38}$ Moreover, I adopt a practical stance towards doing discourse analysis, which means I aim to use analytical insights to develop more productive practices, which for communication skills training in medical education means developing educational practices that advance patient-provider communication with impacts for health outcomes and quality of life. ${ }^{2,39}$

\section{Texts as agents}

Fundamentally, texts like the computerized assessment form I analyze are agents. Texts do things, both on their own and with people. Cooren ${ }^{40}$ describes the hybrid nature of textual agency by discussing how a manager and a Post-It exchange properties. The manager not only writes a reminder on the Post-It, but the Post-It reminds the manager what needs to be done. Texts perform multiple actions: asserting, committing, directing, declaring, and expressing. ${ }^{40}$ It is by analyzing the interactional resources visible in texts that one can more robustly analyze the role of nonhuman agency, and for this project practices that explicate communication skills. 
Texts are strategically written and deployed. Often outliving their original authors texts take on a uniquely independent form. ${ }^{41}$ However, the utterances of authors are a dynamic interplay of voices and values. Intertextuality refers to how texts are embedded with the traces of other texts. ${ }^{42}$ When texts are infused with authoritative discourses, like those of science, psychology, or medicine, they in turn authorize the text and actions it accomplishes.

Analyzing how texts intertextually draw on an authoritative discourse, as well as the pronominal, structural, and punctuational details illustrates how they perform in institutional practice. Forbes ${ }^{43}$ notes how an ADHD screening device is strategically void of first-person pronouns (e.g., A prisoner of the moment), which affords the reader a broad interpretive range (Do I say I'm a prisoner of the moment? Do others say I'm a prisoner of the moment? Am I a prisoner of this moment?, etc.) and leads to a more likely diagnosis of a learning disability. Galasiński's ${ }^{44}$ examination of the Beck Depression Inventory highlights how texts require readers to find themselves within the text (p. 516). When readers are required to answer assessment items, they are restricted to what has been asked and interactively put on the discourse (re)presented (p. 506). ${ }^{45}$

However, texts are not unquestionably adopted. The major findings of the Galasińki's aforementioned study is that participants often reformulate, recontextualize, and challenge assessment items. Similarly, in investigating how quality of life is discussed in psychological interviews, Antaki and Rapley ${ }^{46}$ explain how an interviewer using an institutional interview protocol jointly manages an interaction with a client about their subjective feelings. Even in mainstream communication skills research, there is a recognition that assessment forms may not capture all of a SP's concerns..$^{47}$ The role of texts in SP practices is not to be ignored. While SPs and MSs orient to assessment forms in simulated interactions, what those forms suggest and what actions they perform is not entirely known. Therefore, I begin with explicating and analyzing the particular features of the assessment form.

In sum, by using discourse analysis to the study communication skills training in medical education, I highlight the impacts of human and nonhuman agents, the metadiscursive values of communication skills assessment forms, and the strategies forms use to ensure institutional protocol. I do not answer the question of whether the assessment form accurately represents what communication is, nor do I suggest the assessment form is a lone agent in the construction of communication. My analysis of the form itself is consequential, and through it I aim to contribute to the discourse of communication skills and impact the institution(s) I work with.

\section{The Communication Skills Learning Center}

The CSLC is an associate program developed and used for simulated and experiential learning at a large medical school in the southeastern U.S. CSLC employs a half-adozen staff members and over one-hundred SPs. Staff members schedule and coordinate simulated interactions on behalf of teaching physicians to bring together undergraduate MSs (in their first through fourth year of medical school) and SPs for communication and diagnostic skills trainings. I have spent the last four years conducting fieldwork at the CSLC as well as working as a SP, specifically one trained to complete the form I analyze.

The computerized assessment form I analyze is used to prepare third-year MSs for the USMLE Step 2 CS. SPs are required to attend six-hours of training - three in patient portrayal and three in assessment form completion. Prior to the simulated interactions, SPs receive scripts to memorize, which are designated by a patient name, a sort of textual history taking, and a differential diagnosis. Once SPs arrive on-site, they are assigned clinical examination rooms. Over the course of the day, each SP will see twelve students for no more than fifteen-minutes each and have ten-minutes to complete the computerized assessment form after each simulated interaction. The assessment form contains 37 multiple-choice items and 2 open-ended short answers, for a total of 39-items (Appendix Figure 1). Through my analysis, I point to how the form authorizes persons to accomplish designated actions and regulates degrees of communication skills competency.

\section{Analyzing the Communication Skills Learning Center Step 2 CS Practice Exam assessment form}

\section{Designating tasks}

The SP Post-Encounter Assessment is split into seven sections: Building the Doctor/Patient Relationship, Reflective Listening, Connecting with the Patient, Communications Reflection, History, Physical, Closure and Conclusion to encounter, Follow up and Wrap up. The categories are organized in a chronological fashion, by what the MS should do from the beginning to end in the simulated interaction, which is similar to many popular communication skills models listed above. The categories themselves suggest distinct, unique, and separate phenomenon, which are distinguished in the tasks identified.

First, who should accomplish the tasks? Approximately $92 \%$ (36 of 39) of items follow a similar grammatical structure: beginning with the subject, The student and fitted with a verb or series of verbs (i.e., The student introduced...The student discussed...The student asked...). The only exceptions are item 32, which is formulated as, Did the student... and the two open-ended items. That most items begin with The student implies a context where success is built on student action. Notably, a student is not a practitioner, not a physician, not even a future physician, but one who is learning and has the capacity to improve based on the parameters issued in the text. The structure of each item suggests the capacity for successful commu- 
nication originates from the student because they are accountable for action. Furthermore, even the two openended items explain open-ended items focus on the student: elaborate your reflections on the student and state and additional concerns you would like to share with the student. Skilled communication is therefore a student-centered accomplishment.

\section{Communication skills task types}

While the tasks identified in the form appear to be student-centered accomplishments, a closer analysis suggests otherwise. In creating a taxonomy of task types, I noted how each item requires the MS to act in a particular capacity. However, many items also suggest action on the part of the SP. Therefore, I present the following task types (Appendix Table 1): (1) Medical Student ObjectBased Tasks, (2) Medical Student Assertion-Based Tasks, (3) Medical Student Question-Based Tasks, (4) Medical Student and Standardized Patient Body-Based Tasks, (5) Medical Student and Standardized Patient AssertionBased Tasks, (6) Medical Student and Standardized Patient Question-Based Tasks, and (7) Standardized Patient-Based Tasks.

\section{Medical student object-based tasks}

The first type of task involves the MS and objects: knocking on doors, sanitizing hands, and using a drape. Although the MS does not need the SP to accomplish these tasks, their presence is what makes the task significant. For instance, knocking on a door is given meaning through the context of an exam room and further significance through a patient inside, one who perhaps responds to the knock.

\section{Medical student assertion-based tasks}

Secondly, MSs should initiate utterances that: introduce themselves by name, identify their role, and inquire or explain the purpose of the visit. According to the form, it is the responsibility of the MS to accomplish these actions, they should not require a SP to prompt the statements.

\section{Medical student question-based tasks}

Third, MSs should systematically ask questions about: a chief complaint, a history of smoking, a history of drinking, a history of drugs, what medications the patient takes, if the patient has any allergies, permission to start the physical exam, and if the patient has additional questions or concerns. Again, per the form, these matters should be initiated by the medical student.

\section{Medical student and standardized patient body-based tasks}

While 15 of the tasks should be initiated by the MSs without prompting from a SP, $56 \%$ (22 of 39) tasks significantly rely on SP cooperation. For instance, the fourth type of activity identifies the SPs body as a resource for task completion: maintaining good eye contact and body language, refraining from repeating painful maneuvers, listening to the heart, listening to the lungs, examining the abdomen, and examining extremities and performing reflexes.

\section{Medical student and standardized patient assertion-based tasks}

The fifth and most common type of activity requires MSs to make an utterance that implicates a SP's response: correctly using the patient's name, summarizing concerns, working with the patient to identify main concerns, acknowledging and demonstrating an understanding of feelings, taking personal responsibility where appropriate, valuing choices, behaviors, and decisions, validating and showing understanding for feelings and choices, offering support, requesting additional exams, discussing diagnostic options, providing a differential diagnosis, discussing their initial management plans, mentioning specific tests they'd like to do, and answering final questions or concerns.

\section{Medical student and standardized patient question-based tasks}

In discerning between assertions and questions for activities that suggest only MS involvement, I notice two question-based tasks that explicitly involve both MS and SP: asking open ended questions and actively listening to responses, asking patients to list their concerns and listening to their concerns without interrupting them.

\section{Standardized patient based-tasks}

The final type of activity the form designates occurs post factum. The form requests that SPs elaborate on reflections of the student (from a patient's perspective) and state any additional comments about the encounter. While these are the only two items that explicitly request the SPs perspective, the variation between these two items highlights the complexity of the SP role: one who embodies the imagined patient, offers commentary on the simulated interaction, and accounts for how the assessment form is completed.

Based on the taxonomy of task types, the form explicitly directs SP action in approximately half (56\%) of the designated tasks, either through referencing bodies, assertions they should make, or questions they should respond to. But arguably, SPs are implicated in every one of the items. Even Medical Student and Object-Based Tasks, like The student knocked on the door before entering, are significant through the potential presence of a SP on the other side since just knocking on a door is an otherwise meaningless action. For Medical Student Assertion-Based Tasks, a SP should be there to receive an introduction or to offer a chief complaint; and for Medical Student Question-Based Tasks SPs are required to account for whether the question was asked and are indirectly told to answer it. Therefore, while the assessment form appears to direct 
and regulate MS actions in simulated interactions, it also directs SPs to act as particularly skilled patients and as institutional accountants who create a record of MS action.

\section{The role(s) of the standardized patient}

Through completing the form, SPs create a record of actions taken and assess medical students on a number of points. However, the form is imbued with instructive assumptions of best communication practices for which SP cooperation in both simulated interaction and assessment is taken for granted. The CSCL assessment form regulates communication skills competency through five strategies (Appendix Table 2): (1) extended questions forms, (2) parenthetical sample statements, (3) qualified answers, (4) unqualified items, and (5) open-ended items.

\section{Extended questions}

The first strategy for regulating communication skills competency is through extended questions, or sentences that qualify a communication skills task through further description, either in the sentence or parenthetically. For example, item 27 uses the extended question strategy to direct and regulate the role of the SP in the simulated interaction, which provides implications for MS and their future patients. The item, The student did not repeat painful maneuvers on you when you said it was painful?, suggests SPs are responsible for making pain obvious to the MS during the physical exam and therefore, trains MSs to anticipate particular performances of pain. Item 9, The student summarized my concerns, often using my own words, qualifies how a summary should occur by often using my [the SP's] own words. This item also directs SPs to express concerns (and by proxy assumes future patients will express concerns in a summarizable fashion). Notably, the qualifier in $m y$ own words suggests skilled students join in or align speech styles with the patient.

As a conversation analyst, Stivers ${ }^{48}$ explains how repeating another speaker's utterances in the same or slightly different terms is a modified repeat, which in effect undermines the first speaker's ownership of the claim and asserts the repeater's rights to the claim. The form trains future physicians to use a reclaiming of speech, which strategically makes concerns a matter of medical practice.

While several extended question forms use compound sentences to further qualify communicative actions, others use parenthetical statements. Item 2 requires a MS to introduce themselves by their first and last name, not simply by their first name or by the role they are playing in the simulated interaction (i.e., I'm a member or the team or Hi my name is Grace). The most common extended question form that incorporates a parenthetical qualifier occurs for items in the physical exam section of the assessment form through the statement, (if applicable), which places analytic responsibility on the SP in determining whether a task is applicable to the case they are portraying. How- ever, what constitutes applicable is not obvious in the assessment form and requiring the SP to draw on the script or other knowledge, which may or may not be institutionally based. In sum, extended provides SPs guidelines for their actions and qualifications for completing the computerized assessment form.

\section{Parenthetical sample statements}

Rather than provide the SP information on the conditions of a task or how to complete the assessment form, parenthetical sample statements offer examples of MS talk that demonstrates task completion. For instance, item 7, The student asked an open-ended question and actively listened to the response without interrupting me, parenthetically provides sample statements as a resource for the SP's assessment: (i.e., Can you tell me about... I understand that you are saying... or what happens when...I see, so in other words). This detail focuses SP attention towards canned statements, which is a common feature of communication skills models, literature, and exam requirements.

The use of parenthetical sample statements to explain communication skills tasks are used for abstract concepts like active listening, partnership, empathy, apologizing, and legitimization. The answer structure of such items occludes SP interpretation, assuming the sample statement automatically works and requiring the SP to simply report on whether it occurred. However, SPs and future patients can and often do interpret such statements as insincere or uncaring. ${ }^{23,24,27}$ While the form portrays sample statements as coins MSs can deposit into the conversational black box to achieve particular outcomes, creating an unquestioned if this then that communication equation, it ignores the interactional nature of medical consultations.

Furthermore, the parenthetical sample statements in item 7 are not attached to either open-ended asking or $a c$ tively listening, which suggests the SP can accept the statements accomplish both tasks, regardless of whether they experienced feeling actively listened to. This acceptance is bound by the Not Done/Done answer structure, which constitutes open-ended asking and active listening as joint-actions - two parts of the same action. The further irony of this item is that the medical student must talk for the SP to assess listening, leading to the functioning transaction: if students ask like this, patients will answer, active listening will occur, and in the end medical students will be skilled communicators. Per the form, if the student uttered a statement like the ones listed, the SP can mark, Done. However, if the utterance does not mirror the sample statements offered or if the actions are not done together, the only other option is Not Done.

This item further relies on a black box assumption and overshadows interactional factors of talk. For instance, when patients provide extended accounts of their illnesses or experiences, physicians often perform continuers, which are verbalized tokens of acknowledgment like mhm, yeah, and right. ${ }^{49}$ Such continuers could easily be 
interpreted as interruptions, however such notions of communication are not embedded in the metadiscourse of the assessment form.

\section{Qualified answer forms}

The final strategy for regulating communication skills competency through the assessment form is a qualified answer form. Nearly $70 \%$ of all items (27 of 37) (Appendix Table 3) have two possible answers: Not Done or Done. Placing Done as the second option insists the importance of student action, taking SP cooperation for granted in both (inter)actions and answers. The other 10 items similarly gloss SP cooperation, but further implicate SPs by requiring them to judge medical student performances based on the qualifications described in answer options. These items have three or four options grounded in expectation - with Not Done (or not applicable to the case), Below Expectations, Meets Expectations, and Above Expectations as answer options.

But whose expectations does the form account for? The patient portrayed, whose expectations may be written into the script and imagined by the SP? The SP's, whose expectations are based on their training and experience? Or the student's expectations, based on what they're taught? Attending to the pronouns used in the form offer a path for discerning whose expectation the form refers to. The pronouns me, you, and our, as well as the noun patient are used throughout the document offering contradictory navigational turn-points for form completion. Item 8 , The student asked me to list my concerns and listened to the response without interrupting me, is the first item requiring SPs to elaborate on degrees of communication competency through qualified answers. Notably, it contains four, the most possible, degrees of accomplishment:

(1) Not done;

(2) Below Expectations: Infrequently: The student

kept interrupting me while I was trying to answer

and/or the student kept asking me questions with-

out waiting for a response;

(3) Meets expectations: Mostly: In general, the student asked me my concerns and listened to my

response without interruptions;

(4) Above Expectations: Consistently: The student always asked me to respond do a prompt and waited for my response before moving on.

In this answer, The student and $M e$ are the two agents described. The student asks for a list of concerns and does not interrupt the SP as they offer a response. But what if an actual patient has no concerns? A single concern? This item indicates a preference for the SP to offer a list of concerns and assumes future patients will do the same. This ambiguity highlights a key concern for the use of SPs in medical education: standardization does not account for the skills actual patients may have in communicating with physicians. The possibility of a patient not having a concern, misunderstanding a physician's question for con- cerns, or even offering tokens of acknowledgment in an extended account are ignored potential practices. In other words, students are trained by proficient patients and matters of expectation are not based on the patient's expectation but are dependent on the SP's ability to fulfil their institutional role. This becomes exceedingly concerning for items that measure psychological constructs. For example, item 11 states:

Empathy: The student acknowledged and demonstrated understanding of your feelings (i.e.: that sounds hard,...or, you look upset...) with the answer options:

(1) Not done;

(2) Below Expectations: The student did not acknowledge my feelings very often Infrequently, less than two times;

(3) Meets Expectations: The student consistently acknowledged my feelings and verbalized this in empathy statements.

The pronouns your and $m y$ are used interchangeably. To acknowledge your feelings suggests the medical student acknowledges the feelings of the portrayed patient. However, the answer items use the pronoun $m y$ when referring to feelings, suggesting the SP should use their own feelings to assess student communication competence. However, this pronominal switch does not distinguish the SPs feelings from those of the portrayed patient. Additionally, the parenthetical statements described (that sounds hard...or, you look upset) suggest the utterances will appeal to both parties. This ambiguity ignores the possibility that persons may experience empathy differently and that statements of empathy can be qualitatively different (although the answer types distinguish whether someone meets expectations based on the frequency of offering such statements (i.e., less than two times and consistently)). This item not only ignores the unique experiences of SPs and future patients, but also the actual experience of MSs, who in the context of a simulated interaction are not likely to empathetically engage with who they know is a fake patient, requiring more interactional work to inoculate them against sounding formulaic or insincere (pp. 26-27). ${ }^{23}$ This item demonstrates the dilemma of empathy in communication skills training, which decontextualizes emotions and empathy from the everyday experience of SPs and MSs and creates seemingly observable standards (canned sample statements) that do not work in actual medical practice for the sake of standardized assessable phenomenon.

\section{Unqualified items}

While the strategies of extended questions, parenthetical sample statements, and qualified answers directs both MS and SP actions in simulated interactions as well as metadiscursively regulates communication skills competency, 14 out of 39 questions ( $36 \%$ ) do so without providing additional descriptions. Nonetheless, many of the 
items are based in professional knowledge using terms like chief complaint, history, diagnostic impressions, and management plans in the question stems. Such terms only begin to illustrate how professional knowledge is embedded in the communication skills discourse.

\section{Open-ended items}

Finally, the assessment form has two open-ended questions whose responses certainly merit their own study, but here I emphasize how the questions are structured. Item 17 states, Communications Reflection: Please elaborate your reflections on the student here, discuss what you would have preferred from the patient's point of view. The use of you is once again notable, as it is used in contrast to two other agents: the student and the patient. This suggests that SPs fulfill their institutional role by taking on the imaged perspective of the patient they are portraying. However, the perspective of a patient is just that, a perspective. Within the context of multiple-choice, objective-based questions, such considerations might be seen as secondary. The item also requires the SP to take a critical and potentially negative stance towards a MSs actions. Taking a critical stance is challenging work. Even in face-to-face interactions, criticism is considered a dispreferred response and is often hedged by claims like I think or I feel, which carry less epistemic weight. ${ }^{50}$ Since SPs complete a computerized assessment form, the use of the same interactional resources could further delegitimize their perspective in contrast to the professional knowledge laden, objective-structured questions that make up $95 \%$ of the form.

Item 39, the last item of the form states: General Comments: Please state any additional comments you would like to share with the student regarding their encounter with you. Once again, the pronoun you is used, but here with only in context with the student. This suggests the student is the only recipient of the comments as well as provides SPs a large degree of interpretive freedom: They can offer comments as a SP fulfilling their designated role, a SP's non-institutional perspective, the imagined patient's perspective, or even an amalgamation of the three. That the question is last emphasizes the preference for the previous and first listed closed-ended questions and suggests the previously mentioned items should be taken into consideration along with the short-answer response.

In comparing the Open-Ended Items to the other 37 items of the computerized assessment form, the contrast between professional knowledge and the perspectives of SPs and imagined patients is stark. One is ordered, uniform, terminology-based, and through being multiplechoice suggests a sense of right or wrong. The other is a perspective - just a thought or observation. The semantic weight of the multiple-choice items reinforces the institutionalized version of communication skills over the version of competency described by SPs or the imagined patients they portray.

\section{Discussion}

\section{The implications of assessment forms for communicative practice}

Metadiscursively, the CSCL assessment form emphasizes professional knowledge in SP practices. ${ }^{21} \mathrm{~A}$ shining example is item 10 asks SPs to assess whether The student asked me questions in a systematic and efficient method, asking questions that were logical to follow. The item suggests ideal student questioning is systematic, efficient, and logical to follow, and infers an evaluator's understanding of what is unsystematic, inefficient, and illogical. Thus, a response to this item appears to be based in SP's professional knowledge of history-taking. The candidate assessments create a three-point differentiation based on expectations: i) scattered and organized (and perhaps 'smooth flow'); ii) inefficient, fairly efficient, or efficient; and iii) inaccurate, mostly accurate, or consistently accurate. The differentiation of the answers suggests should master the order, efficiency, and logic of questions together, requiring the SP to be an effective institutional accountant, able to distinguish degrees of ability, based on available resources.

It is key to note that professional knowledge is in many ways antithetical to patient knowledge of medical interactions. This observation is true throughout the form as patient perspectives are often embedded in terms of professional knowledge. Therefore, while SPs are said to offer patient perspectives on a (simulated) medical interaction, they are in fact institutional puppets who by completing the form ventriloquize notions of authoritative communication skills discourse, even in open-ended questions. ${ }^{51}$

Thus, by completing the form, SPs i) create a record of designated student actions performed, which authorizes those actions as facets of communication skills; ii) assess along the continuum of communication skills offered in the form; and iii) proclaim the professional knowledge of communication skills under the guise of a patient perspective. In this, the assessment form not only regulates what the skilled MS should do but imposes institutional expectations of SPs, MSs, and by association patient skills and perspectives. In the following, I consider how the values of communication skills that are visible in the assessment form implicate SPs, MSs, and future patients.

\section{Implications for standardized patients}

Assessment forms strategically direct those who complete them, especially those required to as part of their job. The form suggests SPs are co-operative performers and trained accountants. The form uses multiple strategies to ensure SPs perform and assess an institutionalized version of communication, including extended questions, parenthetical sample statements, 
qualified answers, and shifting pronouns. Convoluted items that assess multiple communication tasks (i.e., open-asking and reflective listening) provide for greater inaccuracies of the tasks measured. Additionally, many items refer to highly abstract concepts, like whether one feels heard or respected. The question and answer structure delegitimizes SP perspectives in Open-Ended Items, whether comments are offered through their own experiences or imagined on behalf of a portrayed patient. Moreover, the institutionalized version of emotional preferences (i.e., empathy and listening) and canned utterances (i.e., in parenthetical sample statements) prevails through the structure of the assessment. By extension, SPs are limited in their unique portrayal of patients and assessment of students from a noninstitutional perspective.

Furthermore, that the form is completed by SPs after the interaction and MSs don't view them until long after the encounter indicates the form reminds SPs what to do and how, not only MSs. Again, $56 \%$ of items rely on an SP to be present, speak, or act. Acting outside of the parameters is consequential - leading to the possibilities of CSCL intervention or even SP termination. In this, the form regulates action and consistently reminds SPs what needs to happen and who needs to do it.

\section{Implications for medical students}

For MSs, the assessment form serves as a structure of practice. Each item emphasizes MS action (The student [verb]) in a particular order (moving from the opening to closing of a medical consultation). However, the student-centered structure of the form conceals how SPs are proficient in the professional knowledge of communication skills in medical education and ignores the role that patients actually play in medical interactions.${ }^{52}$ First, medical students are trained to be competent communicators by interacting with institutionally-trained SPs who have specific knowledge of the assessment form and the professional knowledge it contains (i.e., whether one's history is organized). Furthermore, SPs are limited in their portrayal by the scripts they are issued and the forms they must complete, overshadowing the particularities of patient experience and ability for an institutionalized account of patienthood.

Finally, the assessment form instructs medical students to engage in strategies that enact professional authority in an interaction. ${ }^{53}$ Asking questions in an organized and systematic manner moves the encounter forward according to the provider's expectations. ${ }^{52}$ Modified repeats strategically recontextualize a patient's words under the puview of medical treatment. The irony in teaching these strategies through SP assessment forms is that they suggest these are patient preferences, or a form of patient-centered communication.

\section{Conclusions}

In sum, the assessment form is designed to evaluate student's communication competency, but communication competency cannot exist outside of CSCL's logic of practice. The form designates the tasks that MSs and SPs should accomplish. In designating actions, the form authorizes particular activities, while deauthorizing those not specified. The form regulates a closed-system, which does not account for SP's noninstitutional perspectives, the nuances of MS styles, or the uniqueness of patient experience, in effect decontextualizing communication from an everyday, culturally imbued activity. Instead, communication becomes a professional technology - a tool to accomplish a goal and a method for assessing competence. What is ultimately at risk in this practice is the humanity of SPs, MSs, and especially their patients.

While future studies should attend to the broader experience of standardized patient practice - including how SP cases are written to capture unique patient features, assessment forms are taken up in simulated interactions, as well as how the criteria laid out in them are negotiated by SPs - the findings of this analysis suggest a need to develop more practical tools for training medical students in communication. Furthermore, the rate of physician burn-out and even MS suicide are on the rise, which opens the potential for invoking communication as the universal activity for not only interacting with patients, but with colleagues, and in medical students sensemaking activities as part of professional practice. ${ }^{54}$

I echo the suggestions of interactional scholars, that more efforts should be spent developing a robust vocabulary for students to move forward through personal reflexivity rather than traditional communication skills models which emphasize a student-centered checklist of action. Current paradigms of patient-centered communication skills in SP practices are limited by notions of individual action, abstract emotions, and taken-for-granted notions of patient skills and experiences. Even the more recent shift towards relationship-centered communication skills ${ }^{55}$ that suggest the importance of empathy and affect in patient-provider interaction struggle to offer concrete tools for MS and physicians to reflexively consider their own role in healthcare interactions.

Assessment forms are a key site for designating, authorizing, and regulating professional knowledge and offer key sites for developing protocols that allow MS to advance their reflexive capacities. Discourse analysts, in particular, can offer robust metatheoretical approaches to developing SP practices, cases, and forms that allow for noninstitutional perspectives and capture particularity. Furthermore, discourse analysts can play a key role in developing curricula that are not flat descriptions and tools removed from interactional practices. In each of these opportunities, I echo that the ways we talk about talk is consequential not only for professional practice, but for 
everyday life. Far from being a simple skill, communication is what we make and inhabit.

\section{References}

1. Boisy A, Windover AK, Bokar D, et al. Communication skills training for physicians improves patient satisfaction. J Gen Intern Med 2016;21:755-61.

2. Levinson W, Lesser CS, Epstein RM. Developing physician communication skills for patient-centered care. Health Aff 2010;29:1310-8

3. Levinson W, Roter D, Mullooly JP, et al. Physician-patient communication: the relationship with malpractice claims among primary care physicians and surgeons. JAMA 1997;277:553-9.

4. United States Department of Health and Human Services; 2019. Healthy People 2020. Available from: https://www. healthypeople.gov

5. Association of American Medical Colleges. Contemporary issues in medicine: communication in medicine. Washington DC: Association of American Medical Colleges; 1999.

6. Boulet JR, Smee SM, Dillon GF, Gimpel JR. The use of standardized patient assessments for certification and licensure decisions. Simul Healthc 2009;4:35-42.

7. Barrows HS. An overview of the uses of standardized patients for teaching and evaluating clinical skills. AAMC 1993;68:443-51.

8. Kurtz SM, Silverman J, Draper J. Teaching and learning communication skills in medicine. Abingdon: Radcliffe Medical Press; 1997.

9. Eagles JM, Calder SA, Nicoll KS, Walker LG. A comparison of real patients, simulated patients and videotaped interview in teaching medical students about alcohol misuse. Med Teach 2001;23:490-3.

10. Craig RT. The rhetoric of "dialogue" in metadiscourse: Possibility/impossibility arguments and critical events. In: Weigand E, ed. Dialogue and rhetoric. Philadelphia: John Benjamins; 2008. pp 55-67.

11. Cameron D. Verbal hygiene: the politics of language. New York: Routledge; 1995.

12. Cameron D. Good to talk? Living and working in a communication culture. London: Sage; 2010.

13. Castor T, Bartesaghi M. Metacommunication during disaster response: 'reporting' and the constitution of problems in hurricane Katrina teleconferences. Manag Commun Q 2016;30:472-502.

14. Katriel T, Philipsen G. 'What we need is communication': 'Communication' as a cultural category in some American speech. Commun Monog 1981;48:301-17.

15. Makoul G. Essential elements of communication in medical encounters: the Kalamazoo consensus statement. Acad Med 2001;76:390-3.

16. Epstein RM, Dannefer EF, Nofziger AC, et al. Comprehensive assessment of professional competence: the Rochester experiment. Teach Learn Med 2004;16:186-96.

17. Stewart M. Towards a global definition of patient centered care: the patient should be the judge of patient centered care. BMJ 2001;322:444-5.

18. Swanson DB, van der Vleuten CPM. Assessment of clinical skills with standardized patients: state of the art revisited. Teach Learn Med 2013;25:S17-25.
19. King AM, Hoppe RB. "Best practice" for patient-centered communication: a narrative review. J Grad Med Educ 2013;5:385-93.

20. Vora S, Lineberry M, Dobiesz VA. Standardized patients to assess resident interpersonal communication skills and professional values milestones. West J Emerg Med 2018;19: 1019-23.

21. Sarangi S. Healthcare interaction as an expert communicative system: An activity analysis perspective. In Streeck J, ed. New adventures in language and interaction. Amsterdam: John Benjamins Publishing Company; 2010. pp 167-197.

22. Atkins S, Roberts C, Hawthorne K, Greenhalgh T. Simulated consultations: a sociolinguistic perspective. BMC Med Educ 2016;16:16.

23. Atkins S, Roberts C. Assessing institutional empathy in medical settings. J Appl Ling Profess Pract 2018;13:11-33.

24. Roberts C, Sarangi S. Mapping and assessing medical students' interactional involvement styles with patients. In: Spellman-Miller K, Thompson P, eds. Unity and diversity in language use. London: Continuum; 2002. pp 99-117.

25. Gumperz J. Discourse strategies. Cambridge: Cambridge University Press; 1982.

26. Roberts C, Wass V, Jones R, et al. A discourse analysis of 'good' and 'poor' communication in an OSCE: A proposed new framework for teaching students. Med Educ 2003;37:192-202.

27. Atkins S. Assessing health professionals' communication through role-play: an interactional analysis of simulated versus actual general practice consultations. Discourse Stud 2019;21:109-34.

28. De la Croix A, Skelton J. The reality of role-play: interruptions and amount of talk in simulated consultations. Med Educ 2009;43:695-703.

29. Seale C, Butler CC, Hutchby I, et al. Negotiating frame ambiguity: a study of simulated encounters in medical education. Commun Med 2007;4:177-87.

30. De la Croix A, Skelton J. The simulation game: an analysis of interactions between students and simulated patients. Med Educ 2013;47:49-58.

31. Tracy K. Discourse analysis in communication. In: Scriffin D, Tannen D, Hamilton HE, eds. The handbook of discourse analysis. 2nd ed. Malden, MA, USA: Blackwell Publishers; 2015. pp 725-749.

32. Bartesaghi M, Castor T. Tracing our steps through communication social construction: six propositions for how to go on. In: Galanes G, Leeds-Hurwitz W, eds. Socially constructing communication. Mahwah, NJ: Hampton Press; 2009. pp 225-243.

33. Barad K. Posthumanist performativity: toward an understanding of how matter comes to matter. Signs: J Women Culture Society 2003;28:801-31.

34. Iedema R. Discourse studies in the 21 st century: a response to Mats Alvesson and Dan Kärreman's “Decolonializing discourse." Hum Relat 2011;64:1163-76.

35. Tracy K, Mirivel JC. Discourse analysis: The practice and practical value of taping, transcribing, and analyzing. In: Frey L, Cissna K, eds. Handbook of applied communication. Mahwah, NJ: Lawrence Erlbaum Associates; 2009. pp 153-178.

36. Jones RH. Spoken discourse. London: Bloomsbury Academic; 2016.

37. Kuhn T, Ashcraft KL, Cooren F. The work of communication: relational perspectives on working and organizing in contemporary capitalism. New York: Routledge; 2017. 
38. Stubbe M, Lane C, Hilder J, et al. Multiple discourse analyses of a workplace interaction. Discourse Stud 2003;5:351-88.

39. Antaki C, Billig M, Edwards D, Potter J. Discourse analysis means doing analysis: a critique of six shortcomings. Discourse Anal Online 2003;1. Available from: https:// extra.shu.ac.uk/daol/articles/v1/n1/a1/antaki2002002.html

40. Cooren F. Textual agency: how texts do things in organizational settings. Organization 2004;11:373-93.

41. Smith DE. Texts and the ontology of organizations and institutions. Stud Cult Organ Soc 2001;7:159-98.

42. Bartesaghi M. Intertextuality. In: Tracy K, Ilie C, Sandel T, eds. The international encyclopedia of language and social interaction. New York: Wiley \& Sons; 2015.

43. Forbes S. Measuring disability: The agency of an attention deficit/hyperactivity disorder diagnostic questionnaire. Discourse Stud 2015;17:25-40.

44. Galasiński D. Constructions of the self in interaction with the Beck Depression Inventory. Health 2008;12:515-33.

45. Drew P. Contested evidence in courtroom cross-examination: the case of a trial for rape. In: Drew P, Heritage J, eds. Talk at work: interaction in institutional settings. Cambridge, UK: Cambridge University Press; 1992. pp 470-520.

46. Antaki C, Rapley M. 'Quality of Life' talk: the liberal paradox of psychological testing. Discourse Soc 1996;7:293-316.

47. Blatt B, Plack M, Simmens S, et al. Do standardized patients have concerns about students not captured by traditional assessment forms? Teach Learn Med 2016;28:395-405.

48. Stivers T. Modified repeats: one method for asserting pri- mary rights from second position. Res Lang Soc Interact 2005;38:131-58.

49. Gill VT, Maynard DW. Explaining Illness: patients' proposals and physicians' responses. In: Heritage J, Maynard DW, eds. Communication in medical care: interaction between primary care physicians and patients. London, England: Cambridge University Press; 2006.

50. Pomerantz A. Agreeing and disagreeing with assessments: some features of preferred/dispreferred turn shapes. In: Atkinson M, Heritage J, eds. Structures of social action: studies in conversation analysis. Cambridge: Cambridge University Press; 1984. pp 57-101.

51. Cooren F. Action and agency in dialogue: passion, incarnation, and ventriloquism. Amsterdam, Netherlands: John Benjamins; 2010.

52. Heritage J, Maynard DW, eds. Communication in medical care: interaction between primary care physicians and patients (vol. 20). London, England: Cambridge University Press; 2006.

53. Bartesaghi M. How the therapist does authority: six strategies for substituting client accounts in the session. Commun Med 2009;6:15-25.

54. Pryor L. Doctors are human too. The New York Times 2017. Available from https://www.nytimes.com/2017/04/21/opinion/doctors-are-human-too.html

55. Chou C, Cooley L, eds. Communication rx: Transforming healthcare through relationship-centerd communication. New York, NY: McGraw-Hill; 2018. 